\title{
Lost in Translation? A Systematic Database of Gene Expression in Breast Cancer
}

\author{
Nasser Srour Marc André Reymond Ralf Steinert \\ Department of General, Gastrointestinal and Vascular Surgery, University of Magdeburg, Magdeburg, Germany
}

\author{
Key Words \\ Breast cancer - Adenocarcinoma - Proteomics • \\ Translational research $\cdot$ Gene expression database
}

\begin{abstract}
Ten years of translational research in breast cancer $(B C)$ using high-throughput technologies such as cDNA arrays have produced an impressive amount of results. However, it is difficult for a single researcher to overview these results, since no critical synthesis is provided in the literature. This is a meta-analysis of gene expression in BC. Thirteen translational studies fulfilled the inclusion criteria, involving 553 BC patients and 79 controls. Large cohorts of patients and well-defined samples were rare. A total of 1,350 genes were reported at least once to be deregulated in $\mathrm{BC}$. Out of these findings, 1,212 (90\%) were not confirmed by other authors. A cohort of 138 genes of particular interest remained for further analysis. Of these, 79 were consistently reported to be overexpressed in BC, 41 to be underexpressed and in 18 cases results were contradictory. The most frequently reported deregulated genes in BC include: GATA binding protein 3, arylamine $\mathrm{N}$-acetyltransferase, Myb-related protein $\mathrm{B}$ and zinc transporter SLC39A6 precursor (overexpressed); cadherin-3 precursor, keratin type I cytoskeletal 17 and type II cytoskeletal 5 (underexpressed). These genes obviously correlate with the presence and/or development of BC. More efforts should be devoted to the establishment of common standards in translational $\mathrm{BC}$ research.
\end{abstract}

Copyright $\odot 2008$ S. Karger AG, Basel
(C) 2008 S. Karger AG, Basel

$1015-2008 / 08 / 0752-0112 \$ 24.50 / 0$

Fax +4161306 1234

E-Mail karger@karger.ch

www.karger.com
Accessible online at:

www.karger.com/pat

\section{Introduction}

Breast cancer (BC) is the most common malignant tumor and the leading cause of cancer death in women [1]. Histologically, most BC are adenocarcinomas, and their classification is classically taking into consideration the cell type (as in apocrine carcinoma), the type of secretion (as in mucinous carcinoma), architectural features (such as papillary carcinoma) and spreading characteristics (as in inflammatory carcinoma) [2]. This traditional knowledge is now being augmented by genetic studies: an important discovery in $\mathrm{BC}$ was that germ mutations in 2 genes (BRCA1 and BRCA2) are responsible for approximately two thirds of familial BC [3]. Better molecular understanding of $\mathrm{BC}$ has also permitted the emergence of novel target-directed therapies. For example, overexpression of human epithelial growth factor receptor type 2 (HER2, also referred to as HER2/neu or ErbB-2) occurs in about one fourth of invasive BC. Strategies to target HER2, such as the monoclonal antibody trastuzumab, are effective in treating this subgroup of BC [4].

BRCA and trastuzumab might be only the first chapters of a long story. Novel technologies in translational research have provided powerful tools for further describing, classifying and understanding BC. In particular, over the past decade, DNA microarrays have allowed the measurement of mRNA levels across thousands of genes simultaneously [5]. Microarrays can be applied to analyze gene expression, DNA sequence variation (including the discovery of single nucleotide polymor- 
Table 1. Studies analyzed

\begin{tabular}{|c|c|c|c|c|c|}
\hline Author & Year & Sample origin & Sample preparation & Tumor patients & Controls \\
\hline Amatschek et al. [8] & 2004 & cancer tissue and unpaired normal tissue & whole tissue frozen & 20 & $\begin{array}{l}22, \text { various } \\
\text { tissues, pooled }\end{array}$ \\
\hline Nishidate et al. [9] & 2004 & cancer tissue & laser microbeam microdissection & 81 & - \\
\hline Zhao et al. [10] & 2004 & cancer tissue and unpaired normal tissue & laser capture microdissection & 61 & 3 \\
\hline Garcia et al. [11] & 2005 & cancer tissue and paired (?) normal tissue & whole tissue frozen & 15 & 5 \\
\hline Sorlie et al. [12] & 2001 & cancer tissue and unpaired normal tissue & whole tissue frozen & 81 & 4 \\
\hline Sorlie et al. [13] & 2003 & cancer tissue and unpaired normal tissue & whole tissue frozen & 38 & 4 \\
\hline Bertucci et al. [14] & 2000 & cancer tissue and unpaired normal tissue & macrodissected tissue frozen & 34 & 8 \\
\hline Pollack et al. [15] & 2002 & cancer tissue and cell lines & whole tissue frozen & $44+$ cancer cell lines & - \\
\hline Sotiriou et al. [16] & 2003 & cancer tissue & whole tissue frozen & 99 & - \\
\hline Turashvili et al. [17] & 2007 & cancer tissue and paired normal tissue & laser capture microdissection & 20 & 10 \\
\hline Grigoriadis et al. [18] & 2006 & cancer tissue and unpaired normal tissue & beads-based enrichment & 50 & 10 \\
\hline Di Cristina et al. [19] & 2007 & cancer tissue & whole tissue frozen & 10 & - \\
\hline Axelsen et al. [20] & 2007 & cancer cell lines and normal tissues & pooled & cancer cell lines & $\begin{array}{l}13 \text {, various } \\
\text { tissues, pooled }\end{array}$ \\
\hline
\end{tabular}

phisms), DNA copy number variation, loss of heterozygosity, DNA methylation and transcription factors. The resulting gene expression profiles have provided molecular pathologists with new information on molecular variation between normal and diseased breast tissue, but also on the variability between different $\mathrm{BC}$ and between different individual samples.

In the meantime, terabytes of gene expression data are available to the research community. The number and pace of publications in BC make it difficult, if not impossible, for the individual researcher to keep an overview in his own domain of expertise. Moreover, contradictory results have been reported and there is an increasing number of publications on methodological problems related to DNA array studies. Thus, some researcher might feel 'lost in translation'.

Our group has already gained expertise in merging gene expression data in human cancer $[6,7]$. The aim of the present meta-analysis was to screen the literature for DNA array studies in BC, to select appropriate studies, to merge their results and to compare/contrast these findings, with the hope of identifying molecular key players in $\mathrm{BC}$.

\section{Materials and Methods}

A Medline search of studies published in English using the key words 'breast cancer', 'gene expression' and 'normal' with the limit 'human' was performed. A total of 2,027 abstracts were found. Abstracts of all reports obtained were reviewed and a related article search was performed. Relevant studies were selected by 2 authors (N.S. and M.A.R.), based on compliance with the follow- ing requirements: (1) sample origin: human tissue or human sera or human-derived cell lines; (2) highly paralleled transcriptomics studies; (3) quantitative results on overexpression or underexpression available. Surveys concerning only selected genes and findings based on animal models were not considered. Studies focusing on prognostic factors, therapy response, metastasization and prognostic assessment were excluded.

Gene expression data were categorized as upregulated, downregulated or expressed. Then, data were entered into an Excel (Microsoft Corporation, Redmond, Wash., USA) working sheet. No threshold was defined for up- or downregulation and therefore genes defined as differentially expressed might be only slightly altered in expression. All statistics provided are descriptive and obtained with the built-in tools of the Excel software.

Among various transcriptomics technologies, only cDNA array studies were selected, while serial analysis gene expression studies, for example, were discarded. Results from 13 studies were available [8-20]. When indicated, corresponding supplementary files were downloaded from the publisher's website, as indicated by the authors, and this information was incorporated into the database. This data warehouse was then merged into a single file. SwissProt primary accession numbers were retrieved online (http://www.expasy.ch) between July and October 2007. Gene accession numbers were retrieved from GenBank (http://www.ncbi. nlm.nih.gov/sites/entrez?db=pubmed; search 'nucleotide'). In case of doubt, an Entrez cross-database search was added (http:// www.ncbi.nlm.nih.gov/sites/gquery?term=XXX). Data were then sorted by SwissProt primary accession numbers and double records were merged.

These 13 studies used various samples. Eight surveys analyzed human cancer tissues and unpaired normal tissues [8, 10-14, 17, 18], 2 studies tested only tumor tissue [9, 16], 2 studies compared results from human cancer tissues and tumor cell lines $[15,19]$, and a single survey examined tumor cell lines and normal tissue [20].

The total number of tumor patients profiled in all studies was 553. For comparative analysis, 79 samples from normal tissues obtained at surgery (for example during reduction mammoplasty) were analyzed. An overview of all studies is provided in table 1 . 
Table 2. Genes upregulated in human breast cancer

\begin{tabular}{|c|c|c|c|c|c|c|c|c|c|c|c|c|c|c|c|c|}
\hline AA789233 & P23771 & GATA3_HUMAN & GATA binding protein 3 & & & & & & & & & & & & & \\
\hline D90041 & P18440 & ARY1_HUMAN & arylamine $\mathrm{N}$-acetyltransferase 1 & & & & & & & & & & & & & \\
\hline $\mathrm{X} 14420$ & P10242 & MYBB_HUMAN & Myb-related protein B & & & & & & & & & & & & & \\
\hline $\mathrm{X} 52022$ & Q13433 & S39A6_HUMAN & zinc transporter SLC39A6 precursor & & & & & & & & & & & & & \\
\hline AW949747 & P02461 & CO3A1_HUMAN & collagen alpha-1(III) chain precursor & & & & & & & & & & & & & \\
\hline D90041 & P12111 & CO6A3_HUMAN & collagen alpha-3(VI) chain [precursor] & & & & & & & & & & & & & \\
\hline AA456878 & O60635 & TSN1_HUMAN & tetraspanin-1 & & & & & & & & & & & & & \\
\hline J02874 & P35442 & TSP2_HUMAN & thrombospondin-2 [precursor] & & & & & & & & & & & & & \\
\hline D13665 & P15090 & FABPA_HUMAN & fatty acid-binding protein, adipocyte & & & & & & & & & & & & & \\
\hline Y14690 & Q14534 & ERG1_HUMAN & squalene monooxygenase & & & & & & & & & & & & & \\
\hline $\mathrm{X} 57527$ & Q15012 & LAP4A_HUMAN & lysosomal-associated transmembrane protein $4 \mathrm{~A}$ & & & & & & & & & & & & & \\
\hline
\end{tabular}

Genes quoted 3 times and more are given. Dark grey = Upregulated; bright grey = expressed .

\section{Results}

A total of 1,350 genes were reported at least once to be deregulated in BC. Of these findings, 1,212 (90\%) were reported only once, in other words they were not confirmed by other authors. A cohort of 138 genes of particular interest remained for further analysis. Of these, 79 were consistently reported to be overexpressed in BC, 41 to be underexpressed and in 18 cases the results were contradictory.

\section{Upregulated Genes in Human BC}

Of 79 genes that were consistently reported to be upregulated in BC, 1 gene was found in 6 studies [GATA binding protein 3 (GATA3)], 3 genes in 4 studies [arylamine $\mathrm{N}$-acetyltransferase (NAT) 1 , Myb-related protein B (B-Myb), zinc transporter SLC39A6 precursor] and 12 genes in 3 studies (collagen alpha-1(I) chain [precursor], collagen alpha-2(I) chain precursor, collagen alpha-1(III) chain precursor, collagen alpha-3(VI) chain [precursor], tetraspanin-1, thrombospondin-2 [precursor], fatty acidbinding protein, adipocyte, periostin precursor, platelet glycoprotein 4 , X-box-binding protein 1 , squalene monooxygenase, lysosomal-associated transmembrane protein 4A). These upregulated genes are shown in table 2. Moreover, 63 further genes were reported by 2 authors to be upregulated (online suppl. table 1, www.karger.com/ doi/10.1159/000123849).

\section{Downregulated Genes}

Of 41 genes that were consistently reported to be downregulated in BC, 3 were found in 4 studies (cadherin-3 precursor, keratin type I cytoskeletal 17 and keratin type II cytoskeletal 5). Six genes were reported by 3 authors to be downregulated (chitinase 3-like 2, lactadherin precursor, pleckstrin homology-like domain family A member 1 , tripartite motif-containing protein 29 , bullous pemphigoid antigen 1 and activating transcription factor). These downregulated genes are shown in table 3. Moreover, 32 further genes were reported by 2 authors to be downregulated (online suppl. table 2, www. karger.com/doi/10.1159/000123849).

\section{Deregulated Genes, Contradictory Results}

The expression of numerous further genes has been reported to be deregulated in human BC. However, results reported are contradictory so that these genes appear to be up- or downregulated in different cancers and/ or individuals, possibly in subgroups with typical phenotype. These genes are coding, for example, mucin-like protein 1, annexin A1, tumor necrosis factor and various surface antigens, all proteins with possible involvement 
Table 3. Genes downregulated in human breast cancer

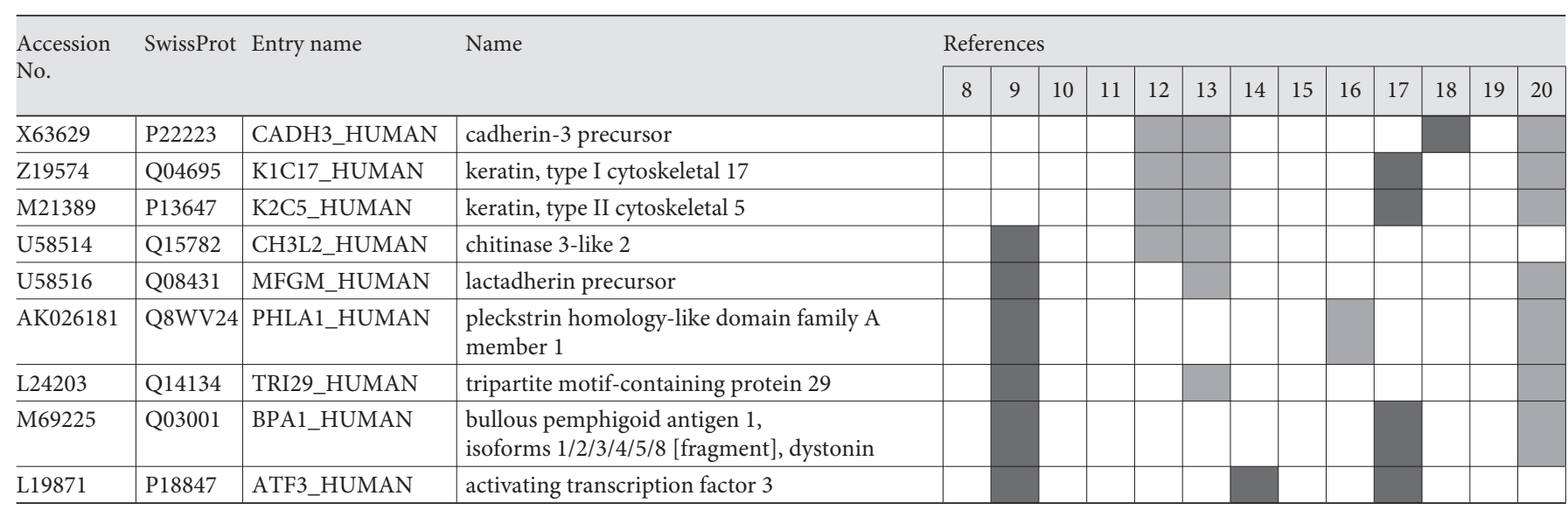

Genes quoted 3 times and more are given. Dark grey $=$ Downregulated; bright grey $=$ expressed.

in carcinogenesis, differentiation, immune response or the metastasization process. These genes are summarized in online supplement table 3 (www.karger.com/ doi/10.1159/000123849).

\section{Discussion}

The aim of the present meta-analysis of gene expression in human BC was to screen the literature for DNA array studies in $\mathrm{BC}$, to select appropriate studies, to merge their results, and to compare/contrast these findings, with the hope of identifying key molecular players in BC.

Our study confirms that a number of studies applying cDNA array technologies in $\mathrm{BC}$ are available, increasing rapidly in numbers, with 173 studies published in the last 12 months. However, our first important observation is that translational studies using cDNA arrays comparing normal tissue with tumor tissue in large cohorts of patients are rare. Only 13 translational studies fulfilled the inclusion criteria, involving $553 \mathrm{BC}$ patients and 79 controls. This figure appears very low, considering that $\mathrm{BC}$ is the most common cancer in women.

Well-characterized samples were also rare. The normal human breast consists of ductal epithelium and surrounding stroma. Breast development requires extensive penetration of the ductal epithelium into the stroma. Thus, it can be expected that analysis of whole tissue biopsies of the breast without separating epithelial from stromal components will induce a significant variability in genome-wide translational research results. This ex- pectation is confirmed by experimental gene expression results: after laser capture microdissection, the stroma and epithelium clustered according to the tissue type and not the presence of tumor [21]. Against this background, it appears disappointing that of the 13 large-scale studies selected for the present meta-analysis, as much as 9 were performed using frozen samples obtained from whole tissue biopsies (stroma and epithelium together) or surgical specimen. Only 4 studies used enriched epithelial cells, 3 by laser microdissection $[9,17], 1$ with beads immunoselection [18]. This is surprising, since cell enrichment techniques have been well validated in $\mathrm{BC}[21,22]$.

A further problem is the definition of normality for comparison purpose and the availability of such control tissue. In BC research, it is obviously a problem to obtain normal tissue. Breast stroma is evolving during pregnancy, lactation and involution, making the definition of normal tissue difficult. In the present meta-analysis, the normal samples represented only $14 \%$ of the number of tumor samples. This low figure is likely to be explained by the small size of $\mathrm{BC}$ and by a trend towards breast-preserving surgery. Perhaps, this also explains why most cDNA array studies in BC, and also the most cited, compare different tumor phenotypes (for example, survival prediction [23], estrogen receptor status [24], nulliparous vs. multiparous [25], response to neoadjuvant therapy [26], molecular portraits [27] and metastasization [28]) rather than tumor with controls. At the end of the day, the information available on specific modifications in gene expression in $\mathrm{BC}$ is scarce. 
A further problem is the bias induced by interindividual variability on gene expression results. Samples from different individuals are expected to show variation in gene expression due to a number of factors, such as difference in tissues, interindividual variation and clinical differences. When these factors were analyzed, the primary source of variation could be attributed to differences between tissues and between individuals [21]. However, only a single, recent study compared paired samples (normal vs. tumor) obtained in single patients, and this only in half the patients (10 of 20) [17].

In spite of all these methodological limitations, this meta-analysis could identify a panel of 138 genes of particular interest in $\mathrm{BC}$, since they are reported to be regularly deregulated in cDNA array studies.

\section{Upregulated Genes}

The most frequently reported deregulated gene in BC is GATA3. GATA3 is a transcriptional activator highly expressed by the luminal epithelial cells in the breast. Patients whose tumors are expressing low GATA3 levels have significantly shorter overall and disease-free survival when compared with those whose tumors had high GATA3 levels. GATA3 had independent prognostic significance above and beyond conventional variables. This result confirms an independent identification of GATA3 as a $\mathrm{BC}$ prognostic marker by global gene expression meta-analysis [29].

Arylamine N-acetyltransferase, a product of the NAT 2 gene, is an enzyme important in carcinogen metabolism via activation and detoxification pathways [30]. NAT2 genetic polymorphism has been reported to be associated with development of BC [31].

$\mathrm{B}-\mathrm{Myb}$ is a transcription factor. Myb has been known for 20 years for being a protooncogene that can be activated by retroviral actions [32]. B-Myb is broadly expressed in rapidly dividing mammalian cells. B-Myb has been shown to promote cell survival by activating antiapoptotic genes and could be implicated in tumorigenesis by regulating gene expression [33].

Zinc transporter LIV-1 (SLC39A6) is a specialist protein controlling the level of intracellular zinc in cells. Zinc plays a vital role in controlling the cellular processes of the cell, such as growth, development and differentiation. SLC39A6 is estrogen regulated and present in increased amounts in estrogen receptor-positive BC as well as in tumors that spread to the lymph nodes. Resistance to antiestrogen drugs such as tamoxifen and fulvestrant often occurs in advanced $\mathrm{BC}$ and is associated with differential expression of individual LIV-1 family members [34].

\section{Downregulated Genes}

Cadherin-3 precursor is downregulated in BC. Loss of expression of the intercellular adhesion molecule E-cadherin frequently occurs in invasive lobular breast carcinomas as a result of mutational inactivation [35]. Cadherins are hormonally regulated cell adhesion proteins that carry out physiological roles during mammary development but have pathological effects when deregulated. Ecadherin expression is irreversibly lost in invasive lobular $\mathrm{BC}$, serving both as a tumor suppressor and an invasion suppressor. Ductal BC involves complex, reversible, epigenetic modulation of multiple cadherins. Transcriptional regulators of E-cadherin have been identified that induce epithelial-to-mesenchymal transitions [36].

Keratins are broadly used in immunohistochemistry laboratories for characterizing adenocarcinomas and defining their organ of origin. Cytokeratin 17 is expressed in the myoepithelium of extralobular ducts of the normal breast tissue, but is not expressed in the vast majority of $\mathrm{BC}$, which do not contain myoepithelial markers (keratin 17 and vimentin) [37]. Cytokeratin 5 is expressed in the basal cells of the breast epithelium. The basal phenotype (expression of cytokeratin 5 and cytokeratin 14) has similar immunohistochemical characteristics with myoepithelial cells of the breast and has poor outcome [38, 39].

Thus, the genes identified with this meta-analysis of gene expression in $\mathrm{BC}$ are key players in the development and/or phenotype of BC. This is a proof of principle for integrating results from cDNA array studies obtained by different authors with independent samples under various experimental conditions.

We believe that performing such meta-analysis of gene expression is a powerful approach for mining the terabytes of data available from the hundreds of gene expression studies in BC. However, this meta-analysis also shows that much more effort should be devoted to the cohort of patients analyzed, to the control tissues and to sample enrichment procedures, as well as to the establishment of common data standards in translational BC research. 


\section{References}

-1 McCracken M, Olsen M, Chen MS Jr, Jemal A, Thun M, Cokkinides V, Deapen D, Ward E: Cancer incidence, mortality, and associated risk factors among Asian Americans of Chinese, Filipino, Vietnamese, Korean, and Japanese ethnicities. CA Cancer J Clin 2007; 57:190-205.

$>2$ Singletary SE: Breast cancer surgery for the 21st century: the continuing evolution of minimally invasive treatments. Minerva Chir 2006;61:333-352.

$>3$ U.S. Preventive Services Task Force: Genetic risk assessment and BRCA mutation testing for breast and ovarian cancer susceptibility: recommendation statement. Ann Intern Med 2005; 143:355-361.

$\checkmark 4$ Hudis CA: Trastuzumab - mechanism of action and use in clinical practice. $\mathrm{N}$ Engl J Med 2007;357:39-51

5 Pollack JR: A perspective on DNA microarrays in pathology research and practice. Am J Pathol 2007;171:375-385.

6 Sagynaliev E, Steinert R, Nestler G, Lippert H, Knoch M, Reymond MA: Web-based data warehouse on gene expression in human colorectal cancer. Proteomics 2005;5:30663078 .

7 Buehrens RI, Amelung JT, Beshay M, Reymond MA: Results of proteomics research in human lung cancer: a meta-analysis. J Proteomics, in press.

$>8$ Amatschek S, Koenig U, Auer H, Steinlein P, Pacher M, Gruenfelder A, Dekan G, Vogl S, Kubista E, Heider KH, Stratowa C, Schreiber M, Sommergruber W: Tissue-wide expression profiling using cDNA subtraction and microarrays to identify tumor-specific genes. Cancer Res 2004;64:844-856.

$>9$ Nishidate T, Katagiri T, Lin ML, Mano Y, Miki Y, Kasumi F, Yoshimoto M, Tsunoda T, Hirata K, Nakamura Y: Genome-wide geneexpression profiles of breast-cancer cells purified with laser microbeam microdissection: identification of genes associated with progression and metastasis. Int J Oncol 2004; 25:797-819

$\checkmark 10$ Zhao H, Langerod A, Ji Y, Nowels KW, Nesland JM, Tibshirani R, Bukholm IK, Karesen $\mathrm{R}$, Botstein D, Borresen-Dale AL, Jeffrey SS: Different gene expression patterns in invasive lobular and ductal carcinomas of the breast. Mol Biol Cell 2004;15:25232536.

11 Garcia N, Salamanca F, Astudillo-de la Vega H, Curiel-Quesada E, Alvarado I, Penaloza $\mathrm{R}$, Arenas D: A molecular analysis by gene expression profiling reveals Bik/NBK overexpression in sporadic breast tumor samples of Mexican females. BMC Cancer 2005;5: 93. $\checkmark 12$ Sorlie T, Perou CM, Tibshirani R, Aas T, Geisler S, Johnsen H, Hastie T, Eisen MB, van de Rijn M, Jeffrey SS, Thorsen T, Quist $\mathrm{H}$, Matese JC, Brown PO, Botstein D, Eystein Lonning P, Borresen-Dale AL: Gene expression patterns of breast carcinomas distinguish tumor subclasses with clinical implications. Proc Natl Acad Sci USA 2001;98: 10869-10874.

13 Sorlie T, Tibshirani R, Parker J, Hastie T, Marron JS, Nobel A, Deng S, Johnsen H, Pesich R, Geisler S, Demeter J, Perou CM, Lonning PE, Brown PO, Borresen-Dale AL, Botstein D: Repeated observation of breast tumor subtypes in independent gene expression data sets. Proc Natl Acad Sci USA 2003; 100:8418-8423.

14 Bertucci F, Houlgatte R, Benziane A, Granjeaud S, Adelaide J, Tagett R, Loriod B, Jacquemier J, Viens P, Jordan B, Birnbaum D, Nguyen C: Gene expression profiling of primary breast carcinomas using arrays of candidate genes. Hum Mol Genet 2000;9:29812991.

15 Pollack JR, Sorlie T, Perou CM, Rees CA, Jeffrey SS, Lonning PE, Tibshirani R, Botstein D, Borresen-Dale AL, Brown PO: Microarray analysis reveals a major direct role of DNA copy number alteration in the transcriptional program of human breast tumors. Proc Natl Acad Sci USA 2002;99: 12963-12968.

16 Sotiriou C, Neo SY, McShane LM, Korn EL, Long PM, Jazaeri A, Martiat P, Fox SB, Harris AL, Liu ET: Breast cancer classification and prognosis based on gene expression profiles from a population-based study. Proc Natl Acad Sci USA 2003;100:1039310398.

17 Turashvili G, Bouchal J, Baumforth K, Wei W, Dziechciarkova M, Ehrmann J, Klein J, Fridman E, Skarda J, Srovnal J, Hajduch M, Murray P, Kolar Z: Novel markers for differentiation of lobular and ductal invasive breast carcinomas by laser microdissection and microarray analysis. BMC Cancer 2007; 7:55.

18 Grigoriadis A, Mackay A, Reis-Filho JS, Steele D, Iseli C, Stevenson BJ, Jongeneel CV, Valgeirsson H, Fenwick K, Iravani M, Leao M, Simpson AJ, Strausberg RL, Jat PS, Ashworth A, Neville AM, O'Hare MJ: Establishment of the epithelial-specific transcriptome of normal and malignant human breast cells based on MPSS and array expression data. Breast Cancer Res 2006;8: R56.

19 Di Cristina M, Minenkova O, Pavoni E, Beghetto E, Spadoni A, Felici F, Gargano N: A novel approach for identification of tumor-associated antigens expressed on the surface of tumor cells. Int J Cancer 2007;120: 1293-1303.
20 Axelsen JB, Lotem J, Sachs L, Domany E: Genes overexpressed in different human solid cancers exhibit different tissue-specific expression profiles. Proc Natl Acad Sci USA 2007;104:13122-13127.

21 Finak G, Sadekova S, Pepin F, Hallett M, Meterissian S, Halwani F, Khetani K, Souleimanova M, Zabolotny B, Omeroglu A, Park $\mathrm{M}$ : Gene expression signatures of morphologically normal breast tissue identify basallike tumors. Breast Cancer Res 2006;8:R58.

22 Balogh GA, Heulings R, Mailo D, Wang R, Li YS, Hardy R, Russo J: Methodological approach to study the genomic profile of the human breast. Int J Oncol 2007;31:253-260.

23 van de Vijver MJ, He YD, van't Veer LJ, Dai H, Hart AA, Voskuil DW, Schreiber GJ, Peterse JL, Roberts C, Marton MJ, Parrish M, Atsma D, Witteveen A, Glas A, Delahaye L, van der Velde T, Bartelink H, Rodenhuis S, Rutgers ET, Friend SH, Bernards R: A geneexpression signature as a predictor of survival in breast cancer. N Engl J Med 2002;347: 1999-2009.

24 West M, Blanchette C, Dressman H, Huang E, Ishida S, Spang R, Zuzan H, Olson JA Jr, Marks JR, Nevins JR: Predicting the clinical status of human breast cancer by using gene expression profiles. Proc Natl Acad Sci USA 2001;98:11462-11467.

25 Balogh GA, Heulings R, Mailo DA, Russo PA, Sheriff F, Russo IH, Moral R, Russo J: Genomic signature induced by pregnancy in the human breast. Int J Oncol 2006;28:399410.

26 Dressman HK, Hans C, Bild A, Olson JA, Rosen E, Marcom PK, Liotcheva VB, Jones EL, Vujaskovic Z, Marks J, Dewhirst MW, West M, Nevins JR, Blackwell K: Gene expression profiles of multiple breast cancer phenotypes and response to neoadjuvant chemotherapy. Clin Cancer Res 2006;12: 819-826.

27 Perou CM, Sorlie T, Eisen MB, van de Rijn M, Jeffrey SS, Rees CA, Pollack JR, Ross DT, Johnsen H, Akslen LA, Fluge O, Pergamenschikov A, Williams C, Zhu SX, Lonning PE, Borresen-Dale AL, Brown PO, Botstein D: Molecular portraits of human breast tumours. Nature 2000;406:747-752.

28 Liu R, Wang X, Chen GY, Dalerba P, Gurney A, Hoey T, Sherlock G, Lewicki J, Shedden K, Clarke MF: The prognostic role of a gene signature from tumorigenic breast-cancer cells. N Engl J Med 2007;356:217-226.

29 Mehra R, Varambally S, Ding L, Shen R, Sabel MS, Ghosh D, Chinnaiyan AM, Kleer CG: Identification of GATA3 as a breast cancer prognostic marker by global gene expression meta-analysis. Cancer Res 2005;65: 11259-11264. 
30 Ochs-Balcom HM, Wiesner G, Elston RC: A meta-analysis of the association of $\mathrm{N}$-acetyltransferase 2 gene (NAT2) variants with breast cancer. Am J Epidemiol 2007;166: 246-254.

31 Huang CS, Chern HD, Shen CY, Hsu SM, Chang KJ: Association between N-acetyltransferase 2 (NAT2) genetic polymorphism and development of breast cancer in postmenopausal Chinese women in Taiwan, an area of great increase in breast cancer incidence. Int J Cancer 1999;82:175-179.

32 Lipsick JS, Baluda MA: The myb oncogene. Gene Amplif Anal 1986;4:73-98.
Sala A: B-MYB, a transcription factor implicated in regulating cell cycle, apoptosis and cancer. Eur J Cancer 2005;41:2479-2484.

34 Taylor KM, Morgan HE, Smart K, Zahari NM, Pumford S, Ellis IO, Robertson JF, Nicholson RI: The emerging role of the LIV-1 subfamily of zinc transporters in breast cancer. Mol Med 2007;13:396-406.

35 De Leeuw WJ, Berx G, Vos CB, Peterse JL, Van de Vijver MJ, Litvinov S, Van Roy F, Cornelisse CJ, Cleton-Jansen AM: Simultaneous loss of E-cadherin and catenins in invasive lobular breast cancer and lobular carcinoma in situ. J Pathol 1997;183:404-411.

36 Cowin P, Rowlands TM, Hatsell SJ: Cadherins and catenins in breast cancer. Curr Opin Cell Biol 2005;17:499-508.
37 Guelstein VI, Tchypysheva TA, Ermilova VD, Litvinova LV, Troyanovsky SM, Bannikov GA: Monoclonal antibody mapping of keratins 8 and 17 and of vimentin in normal human mammary gland, benign tumors, dysplasias and breast cancer. Int J Cancer 1988;42:147-153.

38 Rakha EA, El-Sayed ME, Green AR, Paish EC, Lee AH, Ellis IO: Breast carcinoma with basal differentiation: a proposal for pathology definition based on basal cytokeratin expression. Histopathology 2007;50:434-438.

39 Dabbs DJ, Chivukula M, Carter G, Bhargava $\mathrm{R}$ : Basal phenotype of ductal carcinoma in situ: recognition and immunohistologic profile. Mod Pathol 2006;19:1506-1511. 